\section{CA15.3 measurements for separating FDG PET/CT positive from negative findings in breast carcinoma recurrence}

\section{Factors influencing the area under the ROC curve}

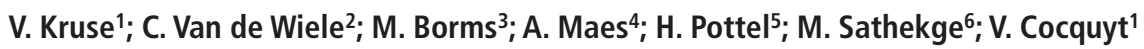 \\ ${ }^{1}$ Division of Medical Oncology, Department of Internal Medicine, University Hospital Ghent, Belgium; ${ }^{2}$ Department of \\ Radiology and Nuclear Medicine, University Ghent, Belgium; ${ }^{3}$ Department of Radiotherapy and Medical Oncology, AZ \\ Groeninge, Kortrijk, Belgium; ${ }^{2}$ Department of Nuclear medicine, AZ Groeninge, Kortrijk, Belgium; ${ }^{5}$ Subfaculty of \\ Medicine, Catholic University Leuven, Campus Kortrijk, Belgium; ${ }^{6}$ Department of Nuclear Medicine, University of \\ Pretoria, South-Africa
}

measurements for CA 15.3 to separate positive from negative FDG PET findings, in ER+ and ER-patients, were respectively $0.772(p=$ $0.0001)$ and $0.596(p=0.143)$. AUC measurements for CA 15.3 to separate positive from negative FDG PET findings, in PR+ and PRpatients, were respectively $0.675(p=0.0001)$ and $0.694(p=0.0001)$. In HER2-positive and -negative patients, the AUC measurements were respectively $0.594(p=0.178)$ and 0.701 $(p=0.0001)$ to separate positive from negative FDG PET findings. Conclusion: The AUC for CA 15.3 measurements to separate FDG PET positive from negative findings in breast cancer patients with suspected recurrence proved to be directly related to the extent of the recurrent disease and hormone receptor status and inversely related to HER2-status. Correcting CA15.3 measurements for blood volumes did not impact the AUC.

\section{Schlüsselwörter}

FDG PET, Brustkrebs, Rezidiv, CA 15.3, ROCKurvenanalyse

\section{Zusammenfassung ((Platz lassen))}

Correspondence to:

Vibeke Kruse, M.D.

Division of Medical Oncology

De Pintelaan 185B, 9000 Ghent, Belgium

\section{((Titiel deutsch................))}

Nuklearmedizin 2014;53:-

http://dx.doi.org/10.3413/Nukmed-0634-13-12

received: December 13, 2013

accepted in revised form: May 13, 2014

epub ahead of print: 
In breast cancer, Cancer Antigen 15.3 (CA 15.3) is considered the serum tumor marker of choice (18). CA 15-3 is an epitope of a large trans-membrane glycoprotein named MUC1 that is derived from the MUC1 gene. Two possible mechanisms have been proposed to account for its production.

- The extracellular domain of MUC1 can be released into serum via proteolytic cleavage.

- Translation products of the MUC-1 gene have been described that lack the trans-membrane and cytoplasmic domain as well as the proteolytic cleavage site that may be directly secreted from the cell, MUC-1/SEC $(17,23)$.

Following curative treatment for breast cancer, limited data suggest that regular serum measurements of CA 15.3 may provide a lead-time of 2-9 months for early recurrence detection $(5,7)$. Accordingly, in

Tab. 1 Patient characteristics

\begin{tabular}{|c|c|c|}
\hline \multicolumn{2}{|c|}{ characteristics $(n=80)$} & \multirow{2}{*}{$\begin{array}{c}\text { value } \\
51.4 \\
30-75.8\end{array}$} \\
\hline age (years) & $\begin{array}{l}\text { mean } \\
\text { range }\end{array}$ & \\
\hline number of PETs & per patient & $1-16$ \\
\hline time interval PE & & $682.6(0-2073)$ \\
\hline $\begin{array}{l}\text { stage at } \\
\text { diagnosis (\%) }\end{array}$ & $\begin{array}{l}\text { I } \\
\text { II } \\
\text { III } \\
\text { IV } \\
\text { NA }\end{array}$ & $\begin{array}{c}19(23.8) \\
26(32.5) \\
23(28.7) \\
8(10) \\
4(5)\end{array}$ \\
\hline $\begin{array}{l}\text { hormonal } \\
\text { receptors, } \\
\mathrm{n}(\%)\end{array}$ & $\begin{array}{l}\text { ER-/PR- } \\
\text { ER+/PR- } \\
\text { ER+/PR+ } \\
\text { ER-/PR+ }\end{array}$ & $\begin{array}{r}12 \\
14 \\
50 \\
4\end{array}$ \\
\hline HER2, n (\%) & $\begin{array}{l}\text { negative } \\
\text { positive }\end{array}$ & $\begin{array}{l}61(76 \%) \\
19(24 \%)\end{array}$ \\
\hline $\begin{array}{l}\text { PET performed } \\
\text { during }\end{array}$ & $\begin{array}{l}\text { All } \\
\text { CT } \\
\text { HT }\end{array}$ & $\begin{array}{l}379 \\
215 \\
164\end{array}$ \\
\hline
\end{tabular}

\begin{tabular}{ll|c|c|c}
\hline \multirow{4}{*}{} & & \multicolumn{3}{l}{ FDG/PET } \\
\cline { 3 - 5 } & & positive, & negative & total \\
\hline \multirow{2}{*}{ CA 15.3 } & positive & 211 & 60 & 271 \\
\cline { 2 - 5 } & negative & 62 & 46 & 108 \\
\cline { 2 - 5 } & total & 273 & 106 & 379 \\
\hline
\end{tabular}

many centres worldwide, serial measurements of CA 15.3 are part of the routine follow-up of breast cancer patients. However, CA 15.3 serum measurements lack specificity and do not predict the number and location of recurrent disease (12). Thus, in clinical practice, CA 15.3 serum measurements are being complemented by conventional morphological imaging or since recently by FDG PET/CT imaging. FDG PET/CT imaging which was shown to have an overall pooled accuracy of $83 \%$ for breast cancer recurrence detection when a CA 15.3 increase is found (8). While CA 15.3 levels have proven systematically higher in PET positive versus PET negative patients, to date no single cut-off value yielding an acceptable accuracy to base the prescription of an FDG PET/CT examination on has been identified. Using various cut-off levels for CA 15.3, sensitivities for FDG PET/CT imaging for breast cancer recurrence detection ranging from $75-96 \%$ and specificities ranging from $50-100 \%$ have been reported $(3,10,16$, 20).

Of interest, CA 15.3 levels have proven directly related to the disease extent (locoregional versus metastatic) and increases are more pronounced and more frequent in hormone receptor positive patients as opposed to hormone receptor negative patients $(17,22,23)$. Also, for similar sized breast lesions producing similar amounts of soluble MUC- 1 in different patients, different CA 15.3 measurements may be obtained due to differences in blood volume; smaller blood volumes will yield higher CA 15.3 measurements. Thus, the aims of this study were to assess the impact of disease extent (loco-regional versus metastatic), hormone receptor status and circulating blood volume on the area-under the ROCcurve of CA 15.3 serum levels for separating FDG PET positive from FDG PET negative findings in breast cancer patients.

Tab. 2

Correlation between FDG-PET and CA 15.3

\section{Patients and methods}

From 2005 until 2013, 379 FDG PET/CT examinations were performed in 80 women suffering from breast carcinoma (51.4 years, 30-75.8 years) who presented with clinical signs suggestive of breast cancer recurrence, doubtful chest and bone radiography and equivocal whole body imaging bone scintigraphy. All patients had been previously treated according to their disease stage and taking into account immunohistochemical features ( Tab. 1). Of the 379 PET/CTs, 164 PETs were performed during hormonal therapy. In patients that had been treated with chemotherapy, a delay of 6 weeks was respected between the date of last treatment and imaging. For all imaging sessions, recent CA 15.3 measurements were available (performed within 7 days of the FDG PET/CT examination). Blood volumes were derived using the formulas by Nadler et al. for men and women based on height and weight (blood volume of men $=0.3669 \mathrm{Ht}^{3}+0.03219 \mathrm{Wt}+0.6041$, blood volume in women $=0.3561 \mathrm{Ht}^{3}+$ $0.03308 \mathrm{Wt}+0.1833(\mathrm{Ht}=$ height in $\mathrm{m}$ and $\mathrm{Wt}=$ weight in $\mathrm{kg}$ ). Blood volumes were multiplied by their corresponding CA 15.3 measurement yielding the total estimated amount of CA 15.3 shedded and/or secreted.

\section{CA 15.3 determination}

CA 15.3 blood levels were assessed using a commercially available radioimmunoassay. Using this assay, abnormal values are defined as $\geq 25 \mathrm{IU} / \mathrm{ml}$.

\section{FDG PET-CT imaging}

FDG PET-CT examinations were performed on a dedicated BGO PET system with a helical CT (discovery ST; GE Medical Systems, Milwaukee, WI, USA). Whole body images (from the base of the skull to the proximal third of the femora) were acquired 60 minutes following the injection of FDG. The dose injected per patient was defined using the following formula (body weight-10) x $3 \mathrm{MBq}$ with a minimum activity of $180 \mathrm{MBq}$ and a maximum activity of $300 \mathrm{MBq}$. Images were reconstructed using an ordered subset expectation maxi- 
mization algorithm provided by the vendor.

\section{Image interpretation}

Two experienced nuclear medicine physicians visually evaluated reconstructed images and in case of discrepancy (none) a final diagnosis was reached by consensus. Any non-physiological, increased FDG uptake with either highly suspicious or definite morphological changes was considered as pathological. The absence of FDG uptake aside from normal physiological uptake was considered as a negative FDGPET-CT examination.

\section{Follow-up}

In all patients, a conclusive diagnosis was obtained from the results of histopathological examination or from clinical/imaging follow-up. Biopsy was not performed if metastases were multiple or bone-relevant. Clinical and radiological recurrences were defined as the detection of recurrent disease by abnormal clinical visit, a continuous rise in CA 15.3 levels or the appearance of new lesions or size increase of old lesions on imaging examinations. For all patients the absence or presence of disease was confirmed by long term follow up with control visits every 3 to 6 months for at least 12 months.

\section{Statistical analysis}

SPSS_version 20.0 was used for statistical analysis. Continuous data were described as mean $+/$ - standard deviation (normal distribution). Comparisons of continuous variables were performed using either an unpaired student t-test (two groups) or ANOVA with post-hoc Bonferroni correction (three groups). Receiver-operatingcharacteristics (ROC)-curve analysis was performed to define the discriminatory value of CA 15.3 measurements as well as blood volume corrected CA 15.3 measurements to separate FDG PET-CT positive (recurrence) from negative (absence of recurrence) findings in various subgroups of patients. To illustrate differences we present data in boxplots whenever relevant.

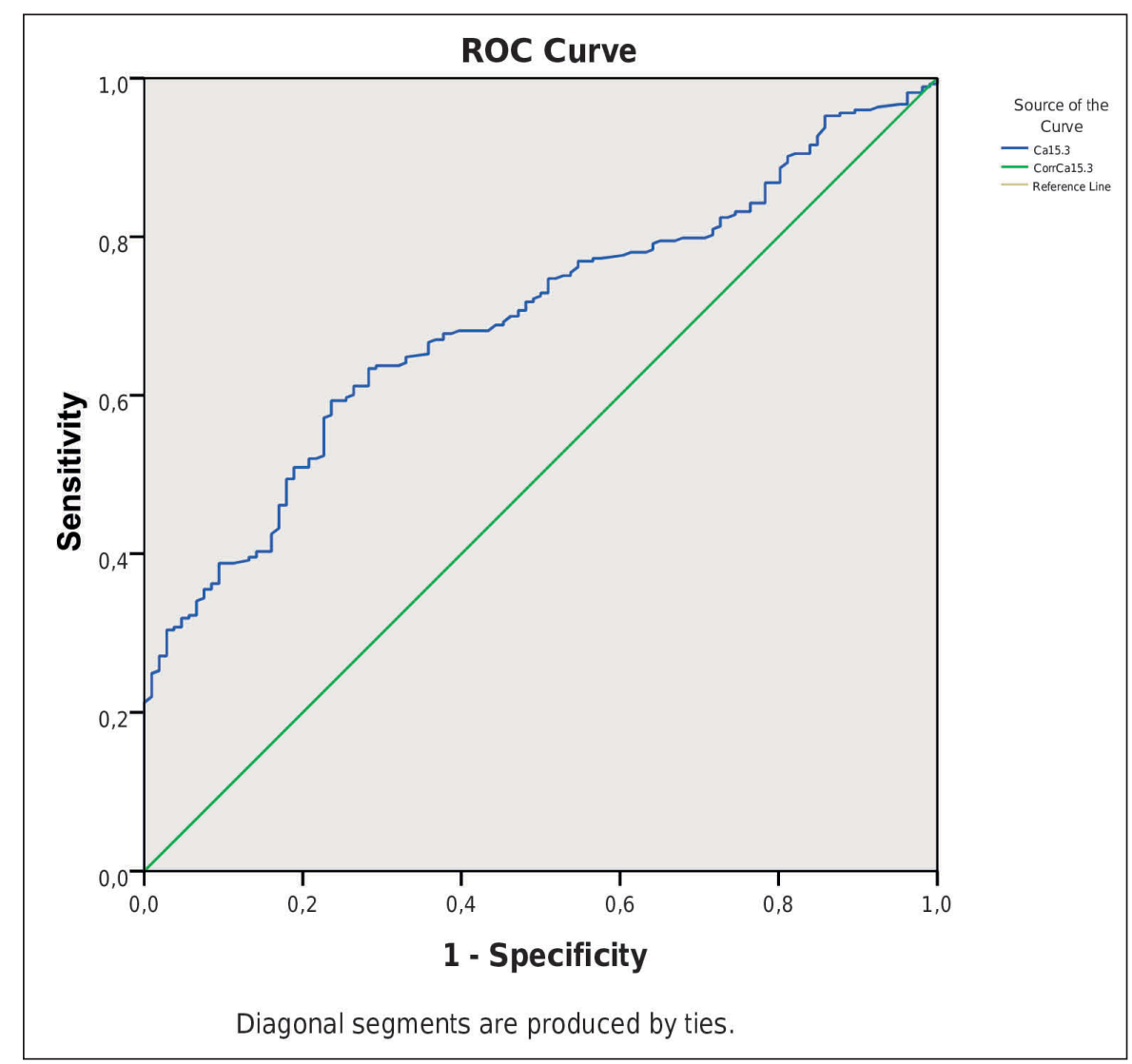

Fig. 1 ROC-curve analysis revealed an AUC of 0.695 with $95 \% \mathrm{Cl}$ : [0.642-0.740] for CA 15.3 to separate FDG PET-CT positive from FDG PET-CT negative findings.

\section{Results}

\section{Whole group}

Patient data are shown ( Tab. 1). CA 15.3 levels varied from $0-1140 \mathrm{IU} / \mathrm{ml}$ (mean: $103.8 \mathrm{IU} / \mathrm{ml}$ (SD: $236 \mathrm{IU} / \mathrm{ml})$. In 273 out of 379 imaging sessions, FDG PET-CT imaging proved positive for malignancy. In 47 sessions, locoregional disease was found. In 226 imaging sessions, metastatic disease was found. In the remaining 106 imaging sessions, FDG PET-CT imaging proved negative for malignancy. Using a cut-off of $\geq 25 \mathrm{IU} / \mathrm{ml}$, increased CA 15.3 values were concordant with imaging results in $257 \mathrm{im}$ aging sessions (both positive in $211 \mathrm{im}$ aging sessions and both negative in $46 \mathrm{im}$ aging sessions) ( $>$ Tab. 2). ROC-curve analysis revealed an AUC of 0.695 with 95\%CI: [0,642-0,740] for CA 15.3 to separate FDG PET-CT positive from FDG PETCT negative findings ( $>$ Fig. 1 ).

\section{Locoregional versus metastatic disease}

FDG PET-CT imaging proved negative in 106 imaging sessions, mean CA 15.3 level was $33.8 \mathrm{IU} / \mathrm{ml}$ (range: $8-127 \mathrm{IU} / \mathrm{ml}$; SD: $22.2 \mathrm{IU} / \mathrm{ml}$ ). In 47 image sessions, FDG PET-CT imaging showed loco-regional disease, mean CA 15.3 level was $55.2 \mathrm{IU} / \mathrm{ml}$ (range: 10-403 IU/ml; SD: $76 \mathrm{IU} / \mathrm{ml}$ ). In the remaining 226 sessions, FDG PET-CT imaging put to evidence metastatic disease (combined with a breast lesion in 29 patients), mean CA 15.3 level was $153 \mathrm{IU} / \mathrm{ml}$ (range: 0-2240: SD: 303 IU/ml). Mean CA 15.3 levels in patients presenting with metastatic disease on FDG PET-CT imaging proved significantly different from that obtained in patients with normal scan findings and patients presenting with locoregional disease ( $\mathrm{p} \leq 0.008)$. Inversely, mean CA 15.3 levels in patients presenting with normal scan findings or presenting with loco-regional disease proved not sig- 


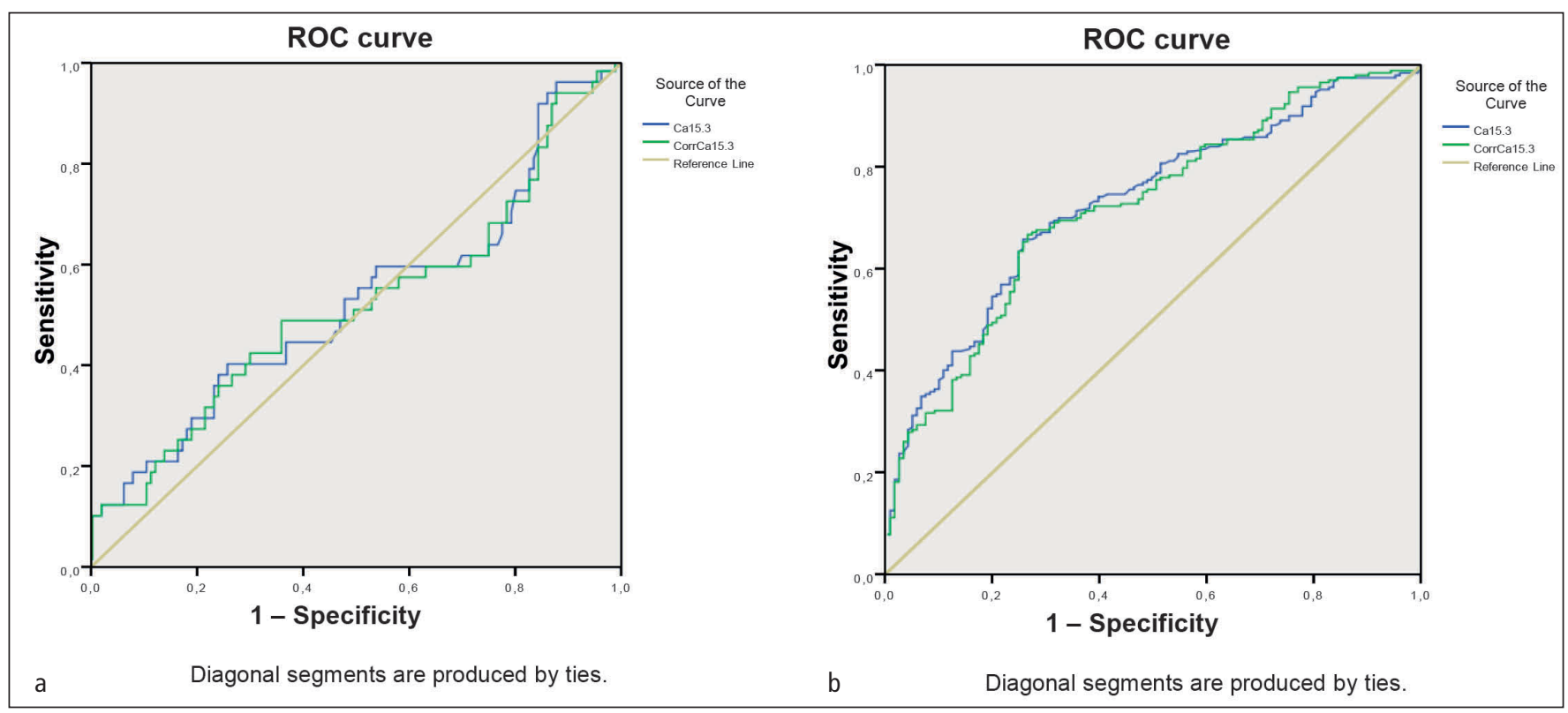

Fig. 2 The area under the CA 15.3 ROC-curve for separating normal scan findings from a) locoregional disease: $0.527(p=0.587) ; b)$ metastatic disease: $0.732(p=0.0001)$

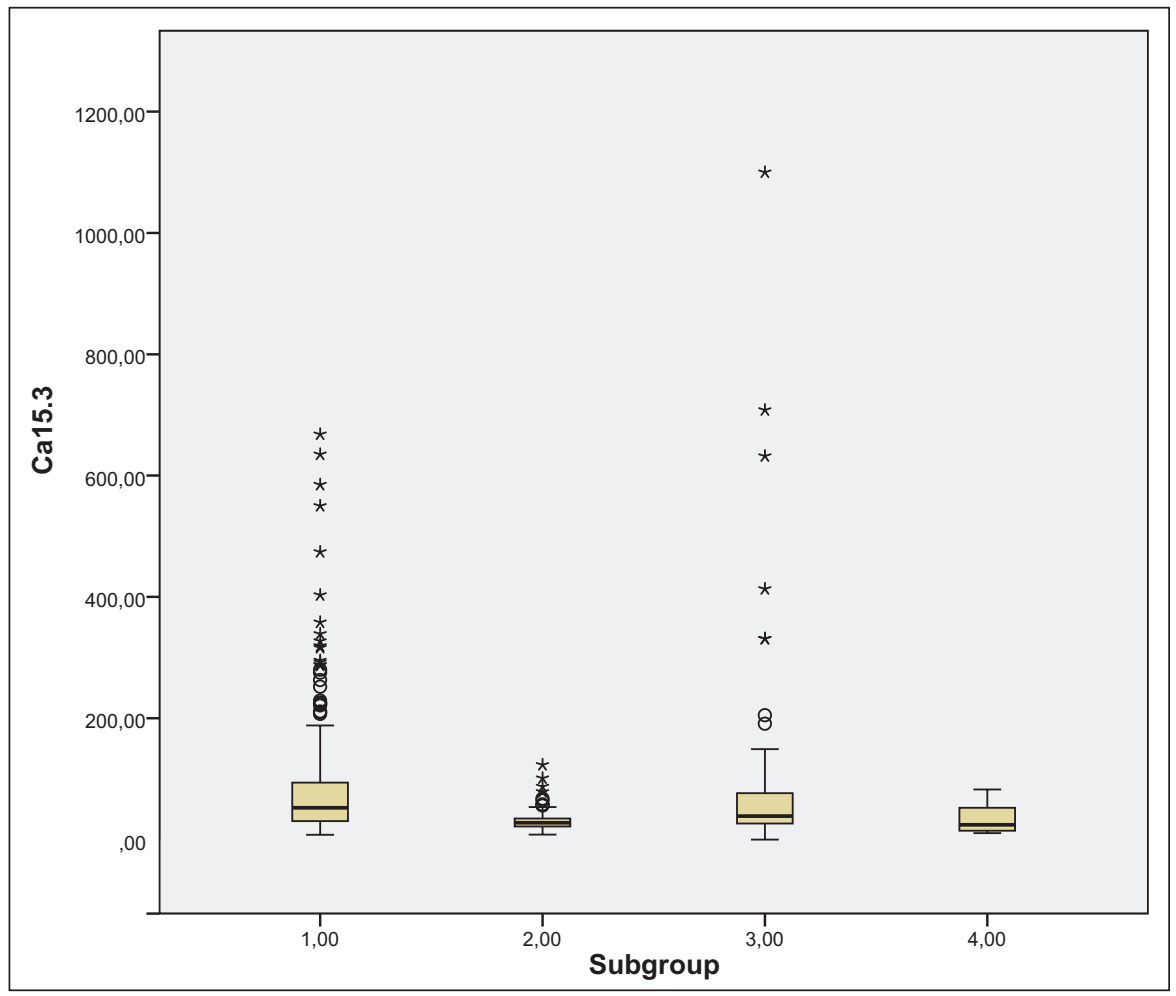

Fig. 3 Measurements of CA 15.3 to separate positive from negative FDG PET-CT scan findings were more pronounced in ER receptor positive than ER-receptor negative patients. This result is in accordance with the ROC-curve analysis (\# 1 ERposPETpos; \# 2 ERposPETneg; \# 3 ERnegPETpos; \# 4 ERnegPETneg).

nificantly different $(\mathrm{p}=0.584)$. The area under the CA 15.3 ROC-curve for separating normal scan findings from metastatic disease was $0.732(\mathrm{p}=0.0001)$. Using a cut- off value of $34.2 \mathrm{IU} / \mathrm{ml}$ a sensitivity of $69 \%$ and specificity of $69 \%$ was obtained. The area under the CA 15.3 ROC-curve for separating normal scan findings from locoregional disease was $0.527(\mathrm{p}=0.587)$ ( $\triangleright$ Fig. 2a, $>$ Fig. 2b).

\section{Receptor status}

CA 15.3 levels measured in estrogen-receptor positive breast carcinoma proved not significantly different from those obtained in estrogen receptor negative breast carcinoma $((\mathrm{n}=82) \mathbb{} \backslash: 73 \mathrm{IU} / \mathrm{ml}$ (range: $0-1100$ $\mathrm{IU} / \mathrm{ml})$ versus $(\mathrm{n}=258) \quad \mathbb{} \times \mathbf{D}: 81 \mathrm{IU} / \mathrm{ml}$ (range: $0-2240 \mathrm{IU} / \mathrm{ml})(\mathrm{p}=0.603))$. AUC's under the curve for CA 15.3 to separate positive from negative FDG PET-CT scan findings, in ER-receptor positive and ERreceptor negative patients were respectively $0.772(\mathrm{p}=0.0001)$ and $0.596(\mathrm{p}=0.143)$. The AUC in ER-negative patients proved significantly smaller when compared to that obtained in ER-positive patients $(\mathrm{p}=$ 0.01) ( Fig. 3).

CA 15.3 levels measured in PR-positive breast carcinoma proved significantly higher compared to those obtained in PRnegative breast carcinoma $((\mathrm{n}=192) \mathbb{\text { W }}: 93$ $\mathrm{IU} / \mathrm{ml}$ (range: 0-1100 IU/ml) versus $(\mathrm{n}=106)$ 呕: $53 \mathrm{IU} / \mathrm{ml}$ (range: 8-708 IU $/ \mathrm{ml})$ $(\mathrm{p}=0.006))(\triangleright$ Fig. $4 \mathrm{a})$. AUCs under the curve for CA 15.3 to separate positive from negative FDG PET-CT scan findings, in PR-positive and PR-negative patients were 
respectively $0.675(\mathrm{p}=0.0001)$ and $0.694(\mathrm{p}$ $=0.0001)(\triangleright$ Fig. 4b, $\triangleright$ Fig. 4c).

CA 15.3 levels measured in HER2-positive breast carcinoma proved not significantly different from those obtained in HER2-negative breast carcinoma $((\mathrm{n}=304)$ W: $108 \mathrm{IU} / \mathrm{ml}$ (range: 0-2240 IU, /ml) versus $(\mathrm{n}=75) \triangle \mathrm{W}: 86 \mathrm{IU} / \mathrm{ml}$ (range: $12-708$
$\mathrm{IU} / \mathrm{ml})(\mathrm{p}=0.465))$. AUC's under the curve for CA 15.3 to separate positive from negative FDG PET-CT scan findings, in HER2-positive and negative patients were respectively $0.594(\mathrm{p}=0.178)$ and $0.701(\mathrm{p}$ $=0.0001)(\triangleright$ Fig. 5). The AUC in HER2-negative patients proved signifi- cantly higher compared to that obtained in HER2positive patients $(\mathrm{p}=0.01)$.

\section{Blood volume corrected CA 15.3 measurements}

Mean blood volume was 4.01 (range: 2.6-6.0 l; SD: 0.6 1). Blood-volume cor-

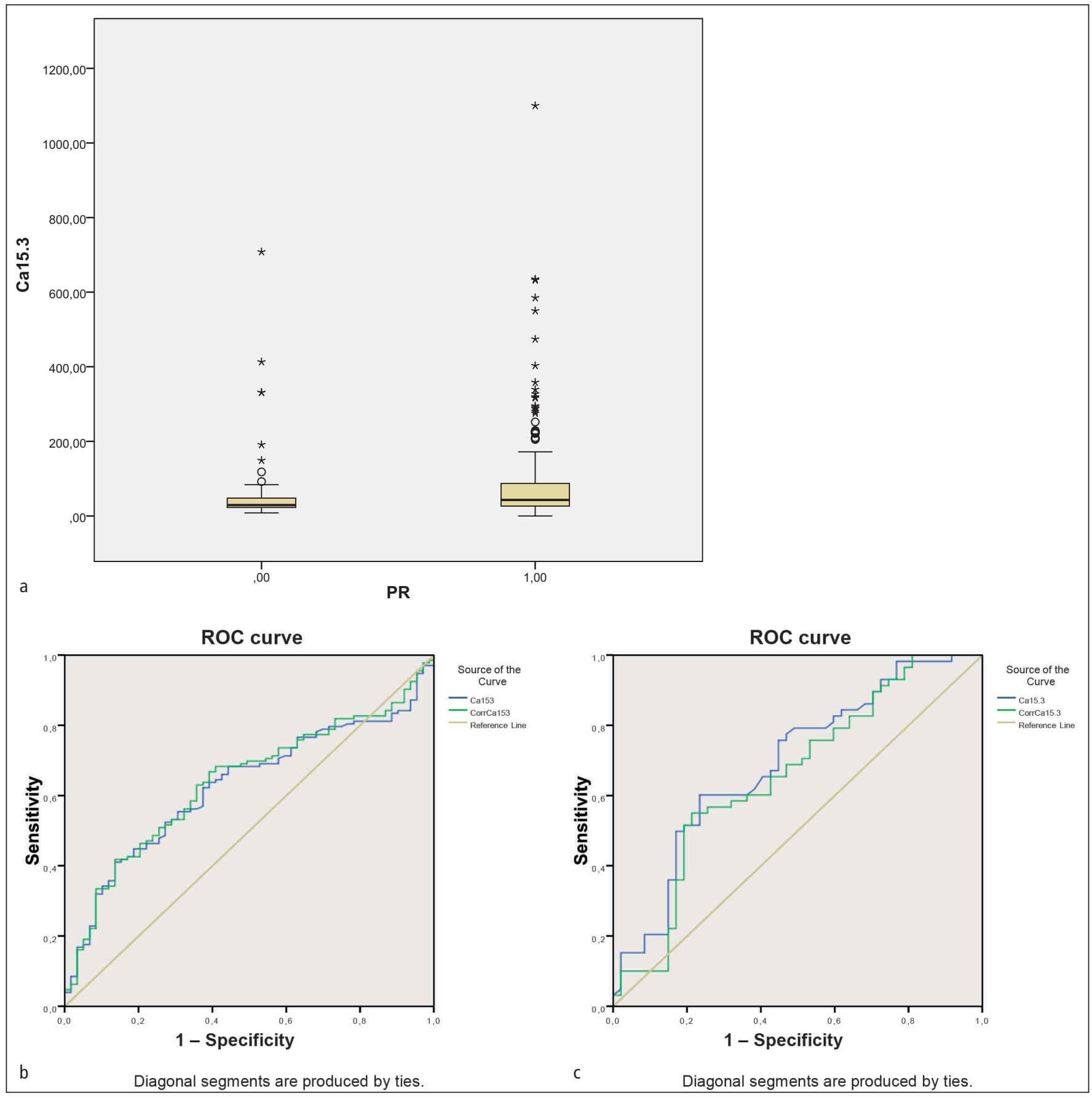

Fig. 4 a) CA 15.3 levels measured in PR-positive breast carcinoma proved significantly higher compared to those obtained in PR-negative breast carcinoma. b, c) AUCs under the curve for CA 15.3 to separate positive from negative FDG PET-CT scan findings, in PR-positive and PR-negative patients were0.675 ( $p=$ $0.0001)$ and $0.694(p=0.0001)$, respectively. 
rected, global CA 15.3 levels varied from 0-12765 IU (mean: 463 IU (SD: 1186 IU). ROC-curve analysis revealed an AUC of $0.670(\mathrm{p}=0.0001)$ for blood-volume corrected total CA 15.3 to separate FDG PETCT positive from FDG PET-CT negative findings, similar to the AUC value for CA 15.3 blood volume uncorrected measurements (see whole group) ( $\triangleright$ Fig. 6a, $>$ Fig. 6b).

\section{Discussion}

In the series presented, mean CA $15.3 \mathrm{lev}$ els in patients presenting with normal scan findings or presenting with loco-regional disease proved not significantly different from each other. The area under the CA 15.3 ROC-curve for separating normal scan findings from locoregional disease was $0.527(\mathrm{p}=0.587)$ suggesting CA 15.3 is neither a sensitive nor specific biomarker for predicting loco-regional recurrence. Previous studies have already shown that serum CA 15.3 levels in patients with localised breast cancer largely overlap those found in healthy women or women with benign breast disease (15). Geraghty et al. studied 129 patients presenting with recurrent breast carcinoma. Out of 14 patients with isolated loco-regional disease, only one patient had increased levels of CA 15.3 (> $25 \mathrm{IU} / \mathrm{ml}$ ) (9). In a series by Hayes et al. including 1050 normal control subjects, 9.4\% of normal controls had CA 15.3 levels greater than $22 \mathrm{U} / \mathrm{ml}$ while that from $5.5 \%$ and $1.3 \%$ had levels greater than $25 \mathrm{U} / \mathrm{ml}$ and $30 \mathrm{U} / \mathrm{ml}$. Inversely, only 13 of $26 \mathrm{pa}-$ tients presenting with loco-regional disease had CA 15.3 levels greater than $22 \mathrm{U} / \mathrm{ml}$ (13). Finally, in a series by Stieber et al. including 272 apparently healthy individuals, 34 pregnant women, 308 benign diseases, 273 cancers other than breast cancer and 439 breast cancer patients, $12 \%$ of patients presenting with benign breast disease had CA 15.3 levels $\geq 25 \mathrm{IU} / \mathrm{ml}$ (21). On the other hand, small clusters of tumoral cells may be missed by FDG PET imaging due to the relatively poor spatial resolution of this imaging modality, around 5-6 mm, and related partial volume effects (11). Inversely, in patients presenting with metastatic disease (with or without associated loco-regional involvement) on FDG PETCT imaging, CA 15.3 values proved significantly higher when compared to patients with normal scan findings or presenting with locoregional disease; using a cut-off value of $34.2 \mathrm{IU} / \mathrm{ml}$ for CA 15.3, a sensitivity and specificity for separating normal scan findings from positive scan findings of both $69 \%$ were obtained. Again, this finding is in line with previous data, respectively reported by Gerachty et al. and Colomor et al. $(6,9)$. In the study by Gerachty et al. 22 out of 23 patients with combined

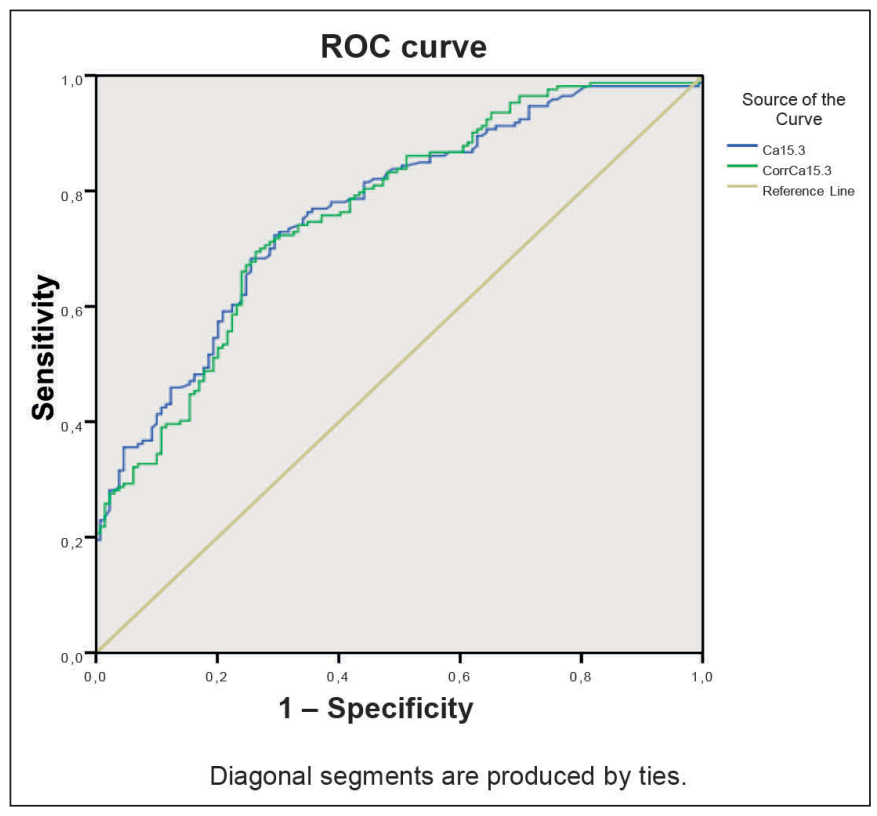

AUCs under the curve for CA 15.3 to separate positive from negative FDG PET-CT scan findings in HER2 negative patients was $0.701(p=0.0001)$. local and systemic disease and 92 out of 115 patients with metastatic disease had increased CA 15.3 levels. The levels of CA 15.3 in the latter group did not differ between single or multiple sites nor between the sites of metastasis (lung, liver and bone) (3). On the other hand, in a series by Colomer et al. in 173 patients with advanced breast carcinoma, elevated CA 15.3 values (greater than $40 \mathrm{IU} / \mathrm{ml}$ ) were seen in 130 patients and values obtained correlated well with the estimated extent of metastatic disease and number of metastases (22).

While in the series presented, CA 15.3 levels proved not significantly different between estrogen-receptor positive and estrogen-receptor negative patients, the AUC value for CA 15.3 to separate positive from negative FDG PET-CT findings in estrogen-receptor positive patients proved significantly higher when compared to that obtained in estrogen- receptor negative patients $(0.772$ versus $0.596 ; p=0.01)$. In the breast cancer cell lines MCF-7 and T47D, MUC-1/SEC was shown to be dependent on estrogen expression; the estrogen receptor alpha could bind estrogen response elements (EREs) that are present in the MUC-1 promotor. In turn, MUC-1 was shown to activate and stabilize ER-á by binding to the DNA-binding domain of the receptor enhancing its activation. Furthermore, MUC1 was shown to promote estradiol mediated growth and survival of breast cancer cells (4). In line with these preclinical findings, Park et al. showed in a series of 707 patients who were diagnosed with metastatic or recurrent breast cancer that supranormal levels of CA 15.3 are more frequently observed in hormone receptor positive patients, estrogen receptor positive and/or progesterone receptor positive (16). Bensouda et al. reported similar findings in a series of 272 patients in whom CA 15.3 was increased in 168 patients at diagnosis of metastases and found to be elevated in $69 \%$ of hormone receptor positive patients versus $46 \%$ of hormone receptor negative patients (2). The close biological link between the secretion and serum levels of MUC-1, from which the CA 15.3 epitope is derived, and estrogen receptor status as suggested by these studies is in line with the higher AUC found in estrogen receptor positive patients 
when compared to estrogen receptor negative patients is not surprising. While expression of the progesterone receptor expression also requires a functional estrogen receptor, similar to MUC-1, in this series, it's absence or presence did not significantly impact the AUC for CA 15.3 suggesting different pathways may be involved regulating their transcription. Of interest, the AUC in HER2-negative patients proved significantly higher when compared to that obtained in HER2-positive patients (0.701 versus $0.594(\mathrm{p}=0.01)$. The inverse relationship between HER2 over-expression and estrogen or progesterone receptor expression is well known $(1,14,19)$. While ER and PR are not an independent predictor for the HER2-status in young women, they are in patients older than 45 years of age (4). In the series presented, the mean age of the patients at the time of diagnosis was 51.4 years, thus the good AUC found in HER2-negative patients in our series is most likely a reflection of the predominant ER-positive status of these patients.

Finally, for similar sized breast lesions producing similar amounts of CA 15.3 in different patients, different CA 15.3 measurements may be obtained due to differences in circulating blood volume; smaller blood volumes are likely to yield higher CA 15.3 measurements.

\section{Limitations}

When performing ROC analysis, ideally one imaging episode/patient should be included in order to avoid too high an impact of a single individual on the area-under the curve. In the series presented, we included several PET-CT imaging data sets per patient. However, as this was the case for all patients included (on average 5 PET-CT examinations per patient) and imaging data sets were acquired over a large period of time, reflecting various clinical situations in one patient, it is unlikely that cutoff values defined in the series presented are impacted significantly by single individuals included in the study. Furthermore, cut-off values identified are similar to those previously reported in the literature.

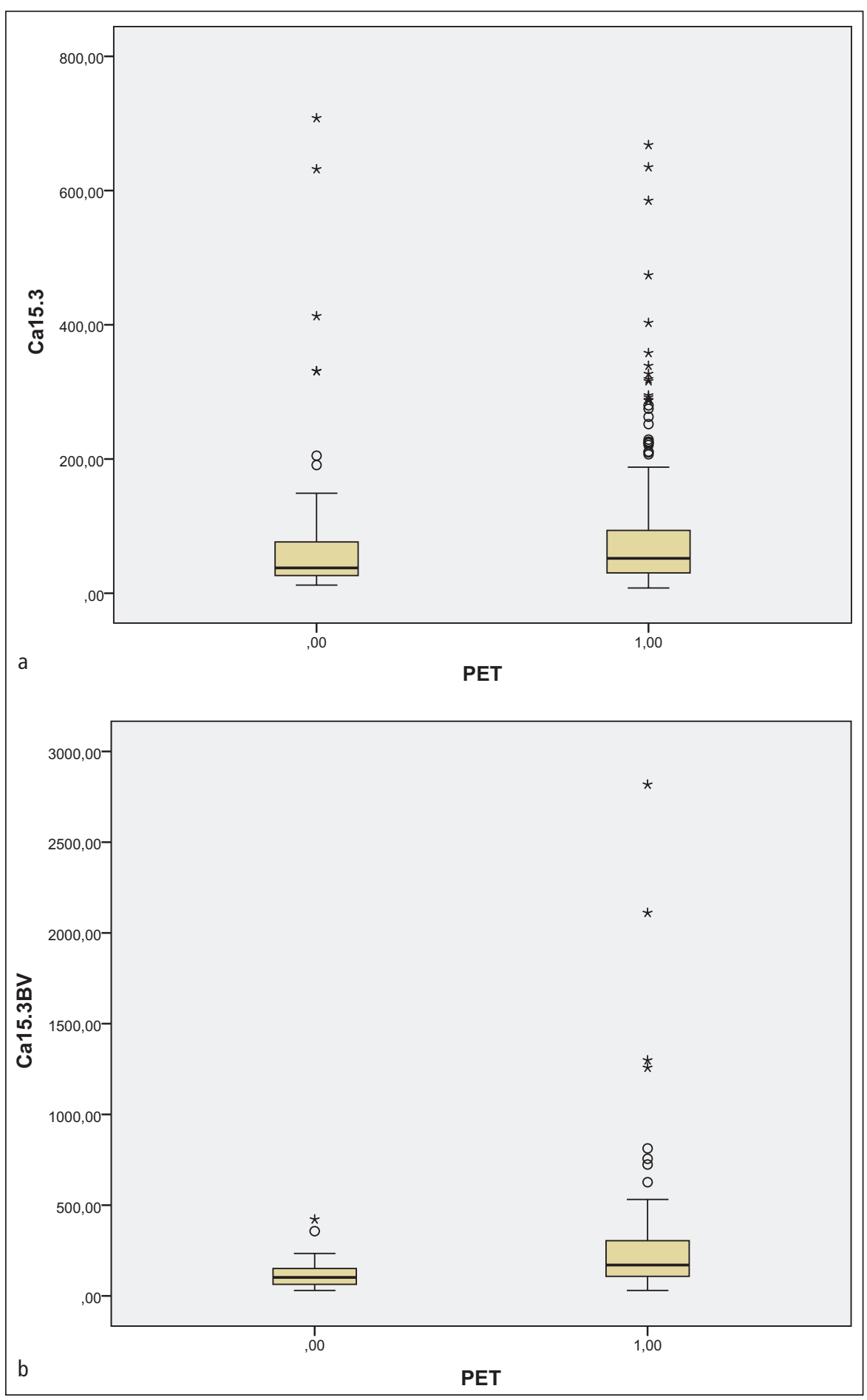

Fig. 6 Ca15.3 measurements (a) and Ca 15.3 corrected for blood volume (b) were significantly higher in patients with a positive PET-scan compared to those obtained in patients with a negative PET-scan.

\section{Conclusion}

In this series, the AUC for CA 15.3 measurements to separate FDG PET/CT positive from negative findings in breast cancer patients in whom a recurrence was suspected proved to be directly related to the extent of the recurrent disease (loco-regional versus metastatic disease) and hormone receptor status (ER + versus ER -) 
and inversely related to HER2 status. The wide variability reported in literature in terms of sensitivity and specificity for identifying breast cancer recurrence using various cut-offs of CA 15.3 to guide FDG PET/ CT imaging may thus in part be explained by differences in proportions of such patients being included. Correcting CA15.3 measurements for blood volumes did not impact the AUC.

\section{Conflict of interest}

The authors declare that

\section{References}

1. Balsari A, Casalini P, Tagliabue E et al. Fluctuation of HER2 expression in breast carcinomas during the menstrual cycle. Am J Pathol 1999; 155: 1543-1547.

2. Bensouda $\mathrm{Y}$, André $\mathrm{F}$, Boulet $\mathrm{T}$ et al. Prevalence of elevated serum CA 15-3 at time of metastatic relapse of breast cancer and correlation with hormone receptor status. Bull Cancer 2009; 96: 923-928.

3. Champion L, Brain E, Giraudet AL et al. Breast cancer recurrence diagnosis suspected on tumor marker rising: value of whole-body ${ }^{18}$ FDG-PET/ CT imaging and impact on patient management. Cancer 2011; 117: 1621-1629.

4. Chekhun S, Bezdenezhnykh N, Shvets J et al. Expression of biomarkers related to cell adhesion, metastasis and invasion of breast cancer cell lines of different molecular subtype. Exp Oncol 2013; 35: 174-179.
5. Cheung KL, Graves CR, Robertson JF. Tumour marker measurements in the diagnosis and monitoring of breast cancer. Cancer Treat Rev 2000; 26: 91-102.

6. Colomer R, Ruibal A, Salvador L.Circulating tumor marker levels in advanced breast carcinoma correlate with the extent of metastatic disease. Cancer 1989; 64: 1674-1681.

7. Duffy M. Biochemical markers in breast cancer which ones are clinically useful? Clin Biochemistry 2001; 34: 347-352.

8. Evangelista L, Cervino AR, Ghiotto $\mathrm{C}$ et al. Tumor marker-guided PET in breast cancer patients-a recipe for a perfect wedding: a systematic literature review and meta-analysis. Clin Nucl Med 2012; 37: 467-474.

9. Geraghty JG, Coveney EC, Sherry F et al. CA 15-3 in patients with locoregional and metastatic breast carcinoma. Cancer 1992; 70: 2831-2834.

10. Grassetto G, Fornasiero A, Otello D et al. ${ }^{18} \mathrm{~F}-\mathrm{FDG}$-PET/CT in patients with breast cancer and rising $\mathrm{Ca}$ 15-3 with negative conventional imaging: a multicentre study.Eur J Radiol 2011; 80: 828-833.

11. Groheux D, Giacchetti S, Delord M et al. ${ }^{18}$ F-FDG $\mathrm{PET} / \mathrm{CT}$ in staging patients with locally advanced or inflammatory breast cancer: comparison to conventional staging. J Nucl Med 2013; 54: 5-11.

12. Harris L, Fritsche H, Menel R et al. American Society of Clinical Oncology 2007 Update of recommendation for the use of tumour markers in breast cancers. J Clin Oncol 2007; 25: 5287-5312.

13. Hayes DF, Zurawski VR Jr, Kufe DW. Comparison of circulating CA15-3 and carcinoembryonic antigen levels in patients with breast cancer. J Clin Oncol 1986; 4: 1542-1550.

14. Huang HJ, Neven P, Drijkoningen $M$ et al. Hormone receptors do not predict the HER2/neu status in all age groups of women with an operable breast cancer. Ann Oncol 2005; 16: 1755-1761.
15. Kokko R, Holli K, Hakama M. Ca 15-3 in the follow-up of localised breast cancer: a prospective study. Eur J Cancer 2002; 38: 1189-1193.

16. Kumita S, Yoshida $\mathrm{T}$ et al. FDG-PET/CT in the diagnosis of recurrent breast cancer. Acta Radiol 2012; 53: 12-16.

17. Park S, Ahn HK, Park LC et al. Implications of different CA 15-3 levels according to breast cancer subtype at initial diagnosis of recurrent or metastatic breast cancer. Oncology 2012; 82: 180-187.

18. Sandri MT, Salvatici M, Botteri E et al. Prognostic role of CA15.3 in 7942 patients with operable breast cancer. Breast Cancer Res Treat 2012; 132: 317-326.

19. Schiff R, Massarweh SA, Shou J et al. Advanced concepts in estrogen receptor biology and breast cancer endocrine resistance: implicated role of growth factor signaling and estrogen receptor coregulators. Cancer Chemother Pharmacol 2005; 56 (suppl 1): 10-20.

20. Schmidt GP, Baur-Melnyk A, Haug A et al. Comprehensive imaging of tumor recurrence in breast cancer patients using whole-body MRI at 1.5 and 3 T compared to FDG-PET-CT. Eur J Radiol 2008; 65: 47-58.

21. Stieber P, Molina R, Chan DW et al. Clinical evaluation of the Elecsys CA 15-3 test in breast cancer patients. Clin Lab 2003; 49: 15-24.

22. Tampellini M, Berruti A, Gorzegno G et al. Independent factors predict supranormal CA 15-3 serum levels in advanced breast cancer patients at first disease relapse. Tumour Biol 2001; 22: 367-373.

23. Wei X, Xu H, Kufe D. MUC1 oncoprotein stabilizes and activates estrogen receptor alpha. Mol Cell 2006; 21: 295-305.

24. Yerushalmi R, Tyldesley S, Kennecke H, et al. Tumor markers in metastatic breast cancer subtypes: frequency of elevation and correlation with outcome. Ann Oncol 2012; 23: 338-345. 